\title{
Effect of growth hormone on bone status in growth hormone- deficient adults
}

\author{
Kuzma $\mathrm{M}^{1}$, Homerova $\mathrm{Z}^{1}$, Dlesk $\mathrm{A}^{1}$, Koller $\mathrm{T}^{1}$, Killinger $\mathrm{Z}^{1}$, Vanuga $\mathrm{P}^{2}$, Lazurova $\mathrm{I}^{3}$, \\ Tomkova $\mathrm{S}^{3}$, Payer $\mathbf{J}^{1}$
}

5th Department of Internal Medicine, Medical Faculty of Comenius University, University Hospital,
Bratislava, Slovakia. kuzmuc@yahoo.com

\begin{abstract}
Background: Growth hormone deficiency (GHD) is associated with reduced bone mineral content and increased risk of osteoporotic fractures. Reduced peak bone mass might explain the low bone mineral density (BMD) among patients with childhood onset GHD (CO-GHD) whilst the cause of osteopenia in adult-onset GHD (AO-GHD) is not fully understood.

Objectives: Prospective multicentric study to asses bone status in GHD adults after two years of recombinant growth hormone replacement treatment.

Methods: In 94 GHD adults (49 men; $\varnothing 34.5 \mathrm{yrs}$ ) we have measured BMD and bone markers (CTX, osteocalcin) during two years of rhGH treatment (at baseline, after 3 and 6 months, and after 1 and 2 years). Patients were adequately substituted for GHD and other pituitary deficiencies.

Results: We have observed an increase in BMD-lumbar spine: $\mathrm{n}=42,0.8155 \rightarrow 0.9418 \mathrm{~g} / \mathrm{cm}^{2}, p<0.0001$; femoral neck $n=41 ; 0.8468 \rightarrow 0.9031 ; p=0.0004$; BMD-whole body $1.0179 \rightarrow 1.0774 ; p=0.0003$. We have compared gender difference: BMD-L-spine by $15.8 \%$ in men $(n=21)$ and by $5.6 \%$ in women $(n=19)(p=0.008)$; BMDfemoral neck increased by $11.03 \%$ in men and by about $3.0 \%$ in women $(p=0.032)$. In women, the initial decrease in BMD was recorded after 3 months. CO-GHD adults yielded a higher increase in BMD -L-spine (16.6 $\%, p=0.022$ ). A correlation exists between IGF-I levels and BMD in lumbar spine (1st year: $R=0.348, p=0.026$; 2nd year: $R=0.33, p=0.0081$ ) and between IGF-I and osteocalcin (1st year: $R=0.383 ; p=0.0038$ ).

Conclusion: Two-year therapy with recombinant human growth hormone improved bone status. IGF-I appears to be a good indicator of rhGH effect on bone (Tab. 3, Fig. 9, Ref. 36). Text in PDF www.elis.sk.

Key words: growth hormone deficiency, bone mineral density, bone markers, IGF-I.
\end{abstract}

Growth hormone deficiency (GHD) is characterized by changes in body composition (BC) such as increased total fat mass, decreased lean body mass (LBM), decreased bone mass, as well as increased prevalence of cardiovascular risk factors and diminished cardiac function (1). Growth hormone (GH) has an anabolic effect on bone in vitro as well as in vivo (2). Those effects are mediated by insulin-like growth factor I (IGF-I) which is produced mostly by the liver. GH and IGF-I are important regulators of bone homeostasis throughout life (3). GH excess, as in acromegaly, has been shown to result in increased bone turnover and bone mineral density $(2,29)$. Deficiencies in both, childhood and adulthood are associated with reduced bone mineral content. Reduced peak bone mass might explain the low bone mineral density (BMD) among patients with childhood GHD (CO-GHD), but the cause of osteopenia in adult-onset GHD (AO-GHD), is not fully understood

${ }^{1} 5$ th Department of Internal Medicine, Medical Faculty of Comenius University, University Hospital, Bratislava, ${ }^{2}$ National Institute of Endocrinology and Diabetology, Lubochna, and ${ }^{3} 1$ st Department of Internal Medicine, Medical Faculty of PJ Safarikiensis University, University Hospital of L Pasteur, Kosice, Slovakia

Address for correspondence: M. Kuzma, MD, 5th Department of Internal Medicine, Medical Faculty of Comenius University, University Hospital, Ruzinovska 6, SK-821 06 Bratislava, Slovakia.

Phone: +421.2 .48234636$
(4). Many authors have observed low BMD in hypopituitarism, especially in growth hormone-deficient patients. The magnitude of bone mass reduction is more marked in adult patients with CO-GHD than in adult patients with AO-GHD (19). Most adults with acquired GHD have a combination of pituitary hormones deficits. As a consequence, many of these patients take hormone replacements that can themselves influence the bone metabolism. These problems can be obviated by studying patients with isolated GHD (IGHD). However, this disease is rare, and IGHD children are often no longer deficient when re-tested as adults (20). The bone remodeling takes time (each cycle is around four months), and GH treatment longer than 18 months is needed to induce bone mineralization and new bone (8).

\section{Aim of the study}

Prospective multicentric study to asses the bone status in GHD adults in response to 2 years of recombinant growth hormone replacement treatment.

\section{Subjects and methods}

A total of 94 adults ( $\varnothing$ age $34.5 \mathrm{yrs}$ ), 49 men ( $\varnothing$ age: 34.02 yrs) and 45 women (average age: 35.2 yrs), with growth hormone 
Table 1: Total number of other pituitary deficiencies (thyroidal, gonadal, adrenocortical axis and antiduretic hormone) in study group. Average number of other pituitary deficiencies was 2,46.

\begin{tabular}{cc}
\hline Number of other deficiencies & Number of patients \\
\hline 0 & 12 \\
1 & 8 \\
2 & 15 \\
3 & 41 \\
4 & 17 \\
\hline
\end{tabular}

Table 2: The survey of GF-I levels during rGH treatment period as comparison adequacy of treatment. All levels were in reference range of IGF-I.

\begin{tabular}{lccc}
\hline & $\mathrm{N}$ & Mean & $95 \%$ CI \\
\hline IGF I month 0 & 94 & 148,412 & $122,527-140,393$ \\
IGF I month 12 & 94 & 154,560 & $131,023-142,000$ \\
IGF I month 24 & 94 & 158,727 & $126,492-144,077$ \\
IGF I month 6 & 94 & 173,312 & $138,679-167,875$ \\
\hline
\end{tabular}

deficiency of adult onset (AO, $\mathrm{n}=67)$ and childhood onset $(\mathrm{CO}$, $n=27$ ) were investigated. Patients were investigated at three centers for treatment of growth hormone deficiency in Slovakia: 5th Internal Clinic of Comenius University and University Hospital, Bratislava, National Institute of Endocrinology and Diabetology, Lubochňa and 1st Department of Internal Medicine of P.J. Šafárik, University Hospital of L. Pasteur, Košice.

The diagnosis of GHD was performed by stimulation testing by means of insulin tolerance test with hypoglycemia (ITT) with regard to valid clinical practice guideline of Endocrine Society for Evaluation and Treatment of Adult Growth Hormone-Deficiency (cut off value of stimulated GH in ITT was $5.1 \mu \mathrm{g} / \mathrm{l}$ ) (21). The patients were divided in 5 groups based on the cause of hypopituitarism as follows: postoperative $(n=61)$, congenital $(n=10)$, idiopathic $(n=17)$, postradiative $(n=5)$ and inflammatory GHD $(n=1)$. Other axis deficiencies are in the Table 1.

All patients were daily administered with a subcutaneous dose of recombinant growth hormone (average doses: baseline $0.25 \mathrm{mg}$, 6th month $0.36 \mathrm{mg}$, 1 st year $0.407 \mathrm{mg}$, 2nd year $0.41 \mathrm{mg}$ ) and adequately treated for other deficiencies. The patients were monitored on regular out-patient basis for target hormone levels. To prove adequate growth hormone replacement treatment we determined the therapeutic range of IGF-I levels (Tab. 2).

At baseline and after 2 years of treatment with rhGH, aAnthropometric measurements have been performed including body height $(\mathrm{cm})$, body weight $(\mathrm{kg})$, waist circumference, and body mass index (BMI).

\section{Laboratory methods}

Measurements of IGF-I levels were provided by an imunoradiometric assay. The assay was established at baseline, after 6 months and 1 and 2 years.

Osteocalcin (OC), marker of osteoformation was established by electrochemoluminiscency (ECLIA) in nanograms per milliliter. Normal range of OC is $6.5-42.3 \mathrm{ng} / \mathrm{ml}$.

Carboxy-terminal collagen crosslinks (CTX, ICTP), marker of osteoresorption was also measured by ECLIA in nanograms per milliliter. Normal range was $0.12-0.74 \mathrm{ng} / \mathrm{ml}$. Both bone markers were established at baseline, after 3 and 6 months, and after 1 and 2 years.

All patients were monitored for levels of serum calcium (S-Ca) at baseline, and after 1 and 2 years. It was in reference range of 2.10-2.55 mmol/l (mean -S-Ca 2,342 mmol/l) during the whole observed period. Forty-one patients were treated with oral calcium (average dose $1000 \mathrm{mg}$ /day). Also, vitamin 25-OH-D3 levels were monitored during the same periods and it was in reference range of 30-80 $\mu \mathrm{g} / 1$ (mean 25-OH-D3 level was $61.3 \mu \mathrm{g} / \mathrm{l}$ ). Thirty-four patients also took oral vitamin D3 (dose $800 \mathrm{IU} /$ day).

\section{Bone mineral density (BMD) measurement}

BMD was measured by Hologic Discovery W .S/N81513 device in $\mathrm{g}$ per $\mathrm{cm}^{2}$. All measurements were performed continuously. BMD was determined in total body, lumbar spine (L2-L4) and proximal femur. Periods of measurement were at baseline, after 3 and 6 months and after 1 and 2 years of growth hormone replacement. Data were expressed as T-score in grams per $\mathrm{cm}^{2}$. The T-score represents the number of standard deviations below the average for a young adult at peak bone density.

\section{Statistics}

Statistic software Medcalc Version 9.6.2.0 was used to determine the results. Student's two-tailed paired t-test was used to assess changes over a two-year period. ANOVA model was used to compare two groups clustered on parameter (gender, onset of deficiency, etc.). We accepted the level of significance at $\mathrm{p} \leq 0.05$.

\section{Results}

\section{Anthropometric characteristics}

Table 3 shows basic anthropometric characteristics of patients in the study group.

\section{Change in BMD after two years of treatment with $r G H$}

After two years of rhGH treatment we have proven an increase in whole-body BMD ( $\mathrm{n}=19$, Mean baseline-2. year: 1.0179$1.0774, \mathrm{p}=0.0003)$. Similarly, there was an increase in BMD in femoral neck $(\mathrm{n}=41 ; 0.8468-0.9031, \mathrm{p}=0.0004)$ and lumbar spine $(\mathrm{n}=42,0.8155-0.9418, \mathrm{p}<0.0001)$ (Fig. 1). We have recorded an initial decrease in BMD in L-spine as well as in BMD in femoral neck after 3 months of rGH therapy. It was similar after 1 year of treatment (Fig. 2).

Table 3: Basic anthropometric characteristics in the study group.

\begin{tabular}{lcccc}
\hline & Mean & Minimum & Maximum & $\begin{array}{c}\text { Difference } \\
\text { P value }\end{array}$ \\
\hline BMI baseline & 27,913 & 17,700 & 47,300 & \\
BMI 2.year & 28,080 & 17,730 & 49,600 & $\mathrm{P}=0,18$ \\
Weight baseline & 77,532 & 36,300 & 138,000 & \\
Weight 2.year & 78,368 & 37,800 & 135,000 & $\mathrm{P}=0,04$ \\
Waist circum. baseline & 93,667 & 69,000 & 131,000 & \\
Waist circum. 2.year & 96,500 & 69,000 & 133,000 & $\mathrm{P}=0,31$ \\
Height baseline & 166,381 & 134,000 & 195,000 & \\
Height 2.year & 166,854 & 134,000 & 195,000 & $\mathrm{P}=0,09$ \\
\hline
\end{tabular}




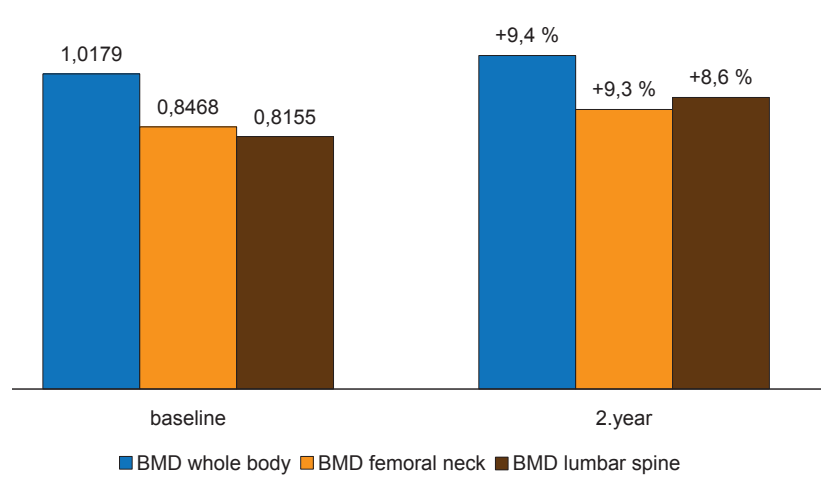

Fig. 1. Increase in BMD of whole body, femoral neck and lumbar spine after two years of treatment with recombinant human growth hormone.

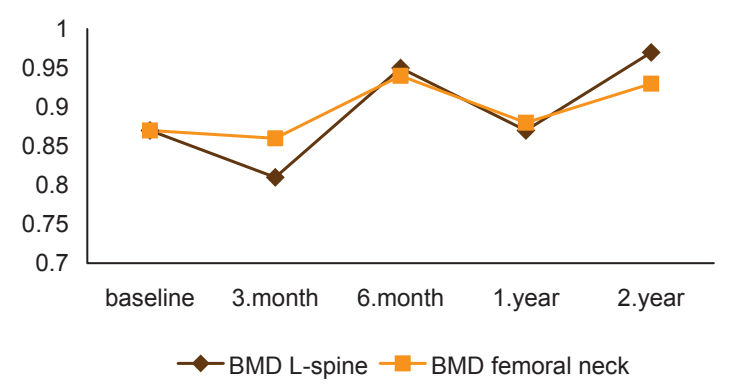

Fig. 2. Development of BMD of femoral neck and lumbar spine.

When we compared groups of men $(n=23)$ and women $(n=19)$ for BMD in L-spine we have recorded that BMD increased after 2 years of treatment (men by more than $15.8 \%$, women more than $5.6 \%, p=0.008$ ) (Fig. 3). A similar situation has occurred in BMD in femoral neck. In group of men $(n=20)$, the increase was by about $11.03 \%$ and in women $(n=21)$ by about $3.0 \%(p=0.032)$ (Fig. 4). It was obvious in both groups that the initial decrease in BMD after 3 months of rhGH treatment was shown preferably in women. While comparing BMD of whole body by gender, no significant result was shown.

Comparing two groups based on onset of GHD we have proven that BMD of lumbar spine increased more in group with childhood

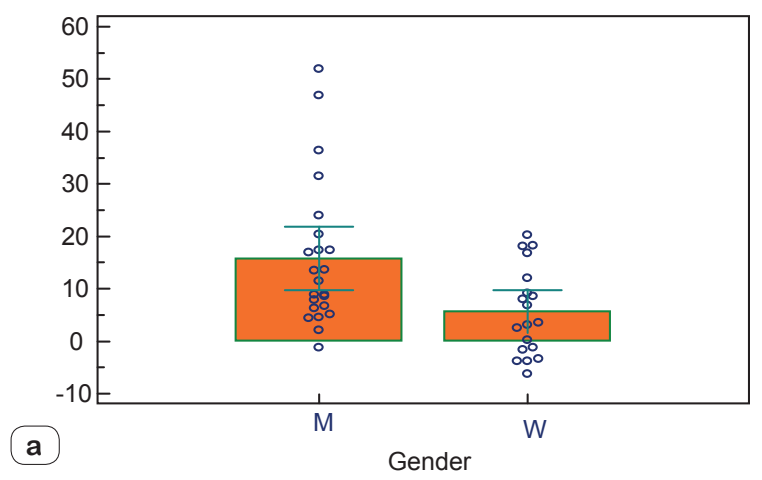

onset of GHD (CO-GHD, $16.6 \%, \mathrm{p}=0.022)$ compared to group with adult onset of GHD (AO-GHD, 7.5\%, p=0.022) (Fig. 5). No significant difference in BMD of femoral neck between these two groups has been shown.

When we were comparing patients by number of other pituitary deficiencies, non-significant $(\mathrm{p}=0.23$ ) difference of BMD was shown between subgroups after two years of treatment. There was a higher increase in patients with three other deficiencies (increase by $14.5 \%$ ) and isolated GHD (increase by $12.4 \%$ ). Also, a nonsignificant difference in BMD $(\mathrm{p}=0.18)$ was observed in groups divided by cause of hypopituiarism. A higher increase was suggested in patients with congenital (by $18.7 \%$ ) and idiopathic (by $14.7 \%$ GHD.

\section{Change in bone markers after two years of treatment with $r G H$}

Carboxy-terminal collagen crosslinks (CTX), marker of bone resorption was increasing during the first year of $\mathrm{GH}$ replacement treatment (mean 3 mth 0.807 , mean 6 mth 1.21, mean 1 year 1.34; $\mathrm{p}<0.0001)$. After one year, i.e. in the second half of treatment, CTX was slightly decreasing (mean 2 yr 1.07; $<<0.0001$ ) (Fig. 6). On the other hand, the levels of osteocalcin, marker of bone formation, were rising during the whole 2-year treatment ( $<<0.0001)$ (Fig. 7).

\section{Correlation between IGF-I and BMD}

At baseline, a significant negative correlation between IGFI and BMD of whole body $(\mathrm{R}=-0.448, \mathrm{p}=0.031)$ has been observed. A positive correlation was noticed between IGF-I levels and BMD of lumbar spine after 1 year $(\mathrm{R}=0.348, \mathrm{p}=0.026)$ (Fig. 8 ) and 2 years $(\mathrm{R}=0.33, \mathrm{p}=0.0081)$ (Fig. 9) of replacement therapy. A positive correlation was noticed in BMD of femoral neck after 2 years $(\mathrm{R}=0.453, \mathrm{p}=0.0002)$ and $\mathrm{BMD}$ of whole body $(\mathrm{R}=0.349$, $\mathrm{p}=0.04)$ of rhGH treatment. A negative significant correlation was observed also between IGF-I and osteocalcin after 1 year $(\mathrm{R}=$ $-0.383 ; \mathrm{p}=0.0038)$.

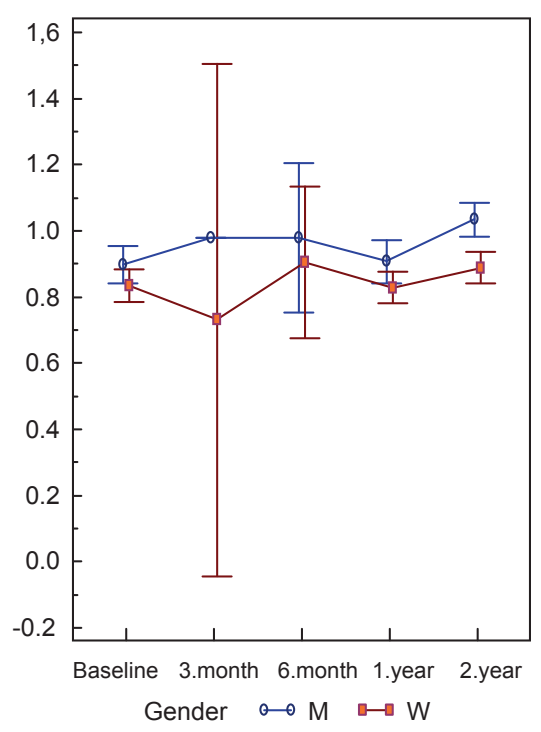

Fig. 3. a) Change in BMD of lumbar spine per gender ( $M$ - men, $W$ - women). b) Development of BMD of lumbar spine per gender. 

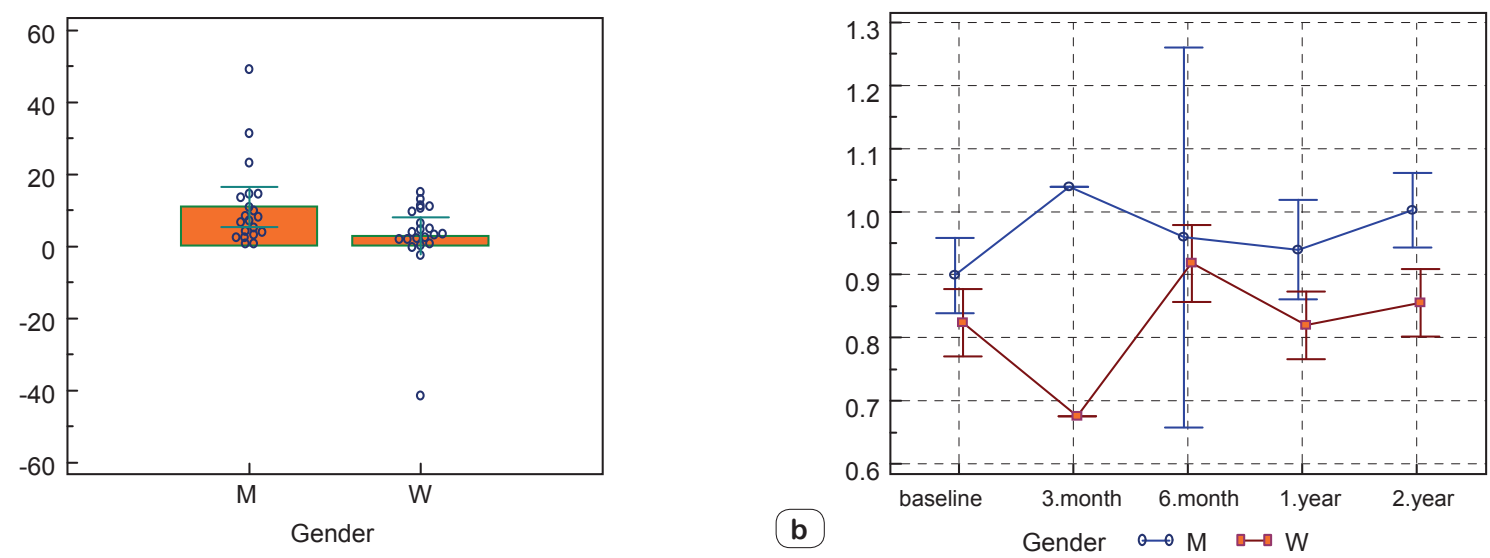

Fig. 4. a) Change in BMD femoral neck per gender ( $\mathrm{M}$ - men, $\mathrm{W}$ - women). b) Development of BMD of femoral neck per gender.

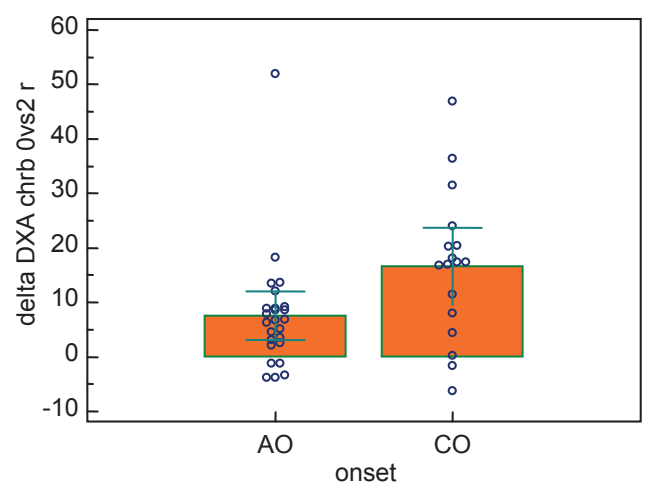

Fig. 5. Comparison of BMD in L-spine between AO-GHD and COGHD adults.

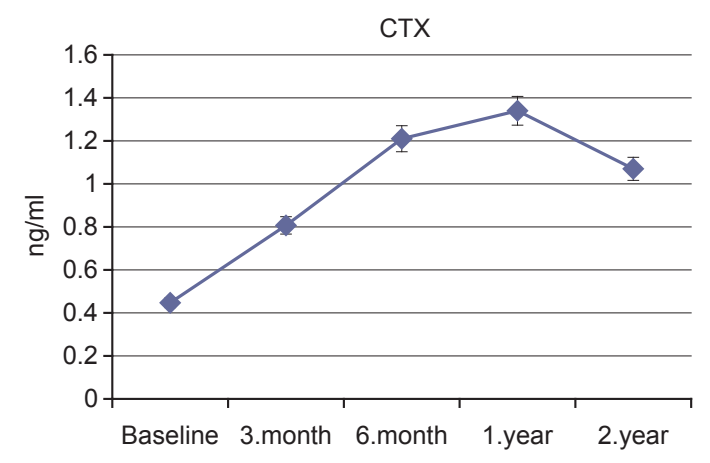

Fig. 6. Change in CTX (carboxy-terminal collagen crosslinks) levels after two years of treatment with recombinant $\mathbf{G H}$.

\section{Discussion}

Therapy with rhGH benefits many body functions, decreases cardiovascular morbidity and mortality, improves lipid profile, body composition, and life quality as well as affects bone remodeling. The effect of rhGH on bone is intensively discussed for the

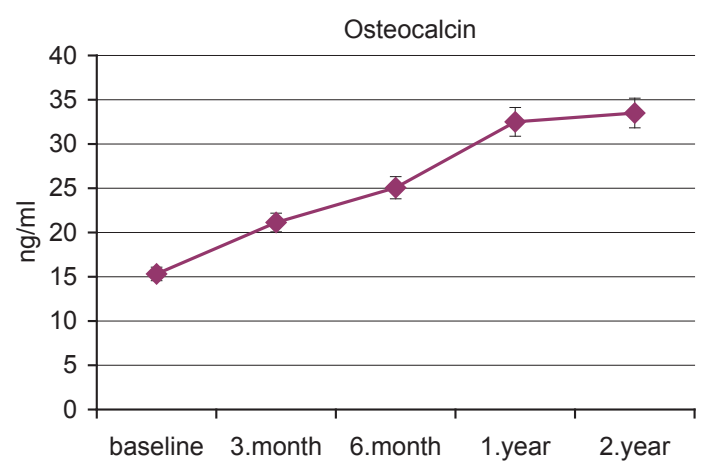

Fig. 7. Change in osteocalcin levels after two years of treatment with recombinant GH.

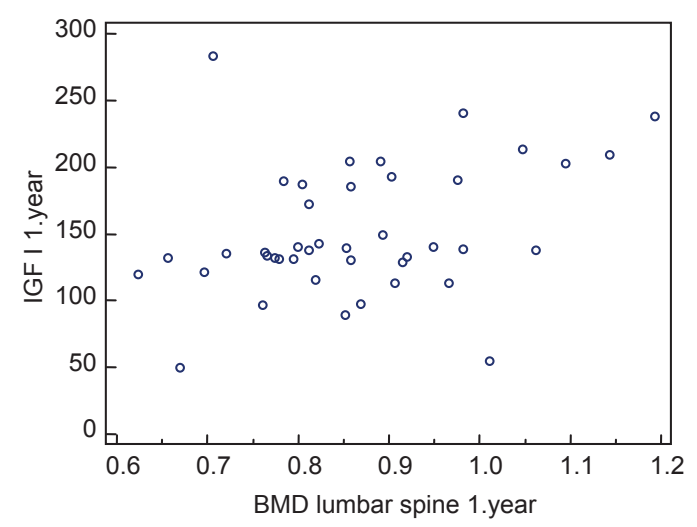

Fig. 8. Correlation between BMD in lumbar spine and IGF-I afer one year.

past few years but there have been only five studies conducted comparing the effect on bone in GHD adults with similar or bigger numbers of patients in study group $(15,17,30,31,32)$. In our prospective study, we have observed 94 patients from three endocrinological centers. We must emphasize that all BMD measurements were provided by one type of device (Hologic Discovery) 


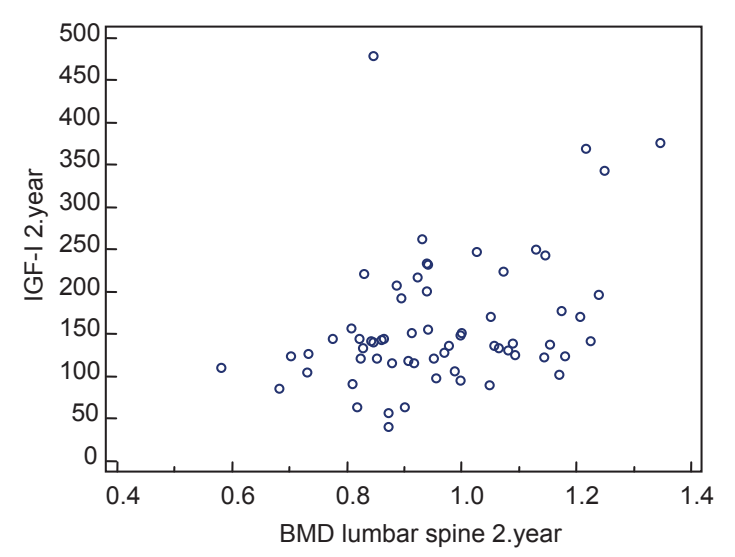

Fig. 9. Correlation between IGF-I and BMD in lumbar spine after two years.

and laboratory assays were evaluated by the same technique. The treatment of adult patients suffering from growth hormone deficiency had a positive effect on BMD. Patients with adult GHD were treated with recombinant human growth hormone (average dose $0.35 \mathrm{mg}$ per day) applied subcutaneously. After two years we have observed an increase in BMD in femoral neck, lumbar spine and whole body. The highest increase in BMD was recorded in lumbar spine. The initial decrease in BMD occurred after three months of rhGH therapy. This displays the initial maximal effect of growth hormone on bone resorption. The effect of rhGH on bone remodeling is biphasic; the maximum effect on bone resorption is brought out after 3 months, and that on bone formation after 6 months (12). As some studies have shown, the initial reduction in BMD takes place after 6-12 months of therapy with recombinant human growth hormone (rhGH). As therapy continues, BMD becomes normal or even higher compared to that at the beginning of therapy $(5,27)$. The sixth month of rhGH therapy is referred to as 'transition point' (28) because at that time the bone formation alternates bone resorption to its maximum effect. When comparing men and women, a higher increase was observed in the group of men (grew by $15.8 \%$ in lumbar spine and by $11.03 \%$ in femoral neck). Male and female patients with GHD may display different responses to rhGH in terms of changes in bone turnover and $\operatorname{BMD}(22,23,24)$. In men, bone formation and resorption increase within 1 month of rhGH treatment, whereas in women, the increase occurs after 3 months $(6,7,9)$ as shown in our study. The increase in markers of bone resorption precedes the change in bone formation markers by about 9 months (9). Our findings support those of few other studies. The early change in bone remodeling may lead to a greater increase in BMD in males than in females, in whom only stabilization of BMD is achieved (10, $11,12,13)$. One of the factor explaining this gender difference is hypogonadism, but minimum of studies exist $(25,26)$. However, in our study, patients with hypogonadism were adequately substituted for this hormonal deficiency. Recent study of Rossini et al (25) confirms that bone responsiveness to GH replacement in GHD adults varies as function of gender even after controlling for potential confounders, and highlights the importance of other cofactors that may affect the interaction between GH replacement therapy and bone remodeling. More interesting findings were made in our study. Patients with CO-GHD have shown a higher increase in BMD than patients with AO-GHD (grew by $16.6 \%$ ). There is a time difference in the increase in BMD between COGHD and AO-GHD. Patients with childhood-onset GHD generally display an increase in BMD after 6 to 12 months of rhGH therapy, whereas patients with adult-onset GHD require 18 to 24 months of rhGH to exhibit a change in BMD (14). This fact could be a sufficient reason to explain different results between AO-GHD and CO-GHD in our work. Despite other research, in which patients with other pituitary diseases (previous Cushing's disease or hyperprolactinemia) have shown a delayed effect in growth hormone replacement compared to patients with nonfunctioning pituitary adenoma (15), in our study, it appears that not only patients with isolated GHD, but also patients with deficiencies of three other pituitary hormones seem to benefit from rhGH therapy and have adequate increase in BMD. The potential reason for non-significance of this finding lies in the limited sample size in subgroups. In our study, the marker of bone formation, osteocalcin, was increasing during the whole two years, whereas CTX showed a decrease after one year of treatment with rhGH. One recent study has compared different functions of osteocalcin and CTX (16). The authors studied 20 individuals (10 men) with IGHD at baseline, after 6 months of depot GH treatment, and 6 and 12 months after discontinuation of GH. The increase in osteocalcin (OC) was more significant during treatment and its reduction was slower after GH discontinuation than in CTX (16). IGF-I as main mediator of GH function plays an important role also in bone remodeling. Our findings confirm that a positive correlation exists between IGF-I levels and BMD. We have observed that there exists also a negative correlation between these two parameters at the baseline (in not treated adults). It was also confirmed by Rota et al (17) who found a significant correlation between plasma IGF-I levels and T-score at the lumbar spine and femoral neck, serum OC and urinary Ntx (cross-linked N-telopeptides of type I collagen) levels. A multiple correlation analysis revealed that the T-score at the lumbar spine, but not at the femoral neck, was more strongly predicted by plasma IGF-I levels (17). To resume, the replacement therapy with rhGH leads to an increase in bone turnover, as determined by changes in biochemical markers of bone resorption and bone formation (18). Patients with GHD have also an increased incidence of vertebral deformities, suggesting an increased incidence of vertebral fractures (33). The prevalence of bone fractures is related to the degree of GHD and seems not to be affected by the presence of other pituitary hormone deficiencies or by hormonal replacement therapy $(34,35$, 36). In our study, no osteoporotic fracture has been noticed, probably due to a limited number of patients in study group. Our study has demonstrated that therapy with recombinant human growth hormone can lead to increased BMD in lumbar spine and femoral neck. This increase in bone mineral density can protect patients from future osteoporotic fracture. Another proof that rhGH improves bone mineral content lies in an increase in bone markers 
689-695

with a sustained higher activity of bone formation markers. Apart from its importance in monitoring the adequate treatment, IGF -I appears to be a good indicator of the effect of rhGH on bone.

\section{Conclusion}

In our multicentre prospective study, it has been observed that two-year therapy with recombinant human growth hormone leads to an increase in BMD and markers of bone formation as well as to a decrease in clinical fractures and markers of bone resorption. Based on these findings, we believe that the therapy with recombinant human growth hormone is the most physiological treatment modality in secondary osteoporosis in growth hormonedeficient adults.

\section{References}

1. de Boer H, Blok GJ, Van der Veen AE. Clinical aspects of growth hormone deficiency in adults. Endocrine Rev 1995; 16: 63-86. doi:10.1210/ edrv-16-1-63.

2. Gillberg P, Mallmin H, Petrén-Mallmin M, Ljunghall S, Nilsson AG. Two years of treatment with recombinant human growth hormone increases bone mineral density in men with idiopathic osteoporosis. J Clin Endocrinol Metab 2002; 87 (11): 4900-4906.

3. Giustina A, Mazziotti G, Canalis E. Growth hormone, Insulin-like Growth factors,and the skeleton. Endocrine Rev 2008; 29 (5): 535-559.

4. Rosen T, Wilhelmsen L, Landin-Wilhelmsen K, Lappas G, Bengtsson BA. Increased fracture frequency in adult patients with hypopituitarism. Eur J Endocrinol 1997 (137): 240-245.

5. Kužma M, Payer J. Growth hormone deficiency, its influence on bone mineral density and risk of osteoporotic fractures. Cas Lek Cesk 2010; 149 (5): 211-216.

6. Brixen K, Nielsen HK, Mosekilde L, Flyvbjerg A. A short course of recombinant human growth hormone treatment stimulates osteoblasts and activates bone remodeling in normal human volunteers. J Bone Miner Res 1990; 5 (6): 609-618.

7. Johansson AG, Lindh E, Blum WF, Kollerup G, Sørensen OH, Ljunghall S. Effects of growth hormone and insulin-like growth factor I in men with idiopathic osteoporosis. J Clin Endocrinol Metab 1996; 81 (1): 44-48.

8. Landin-Wilhelmsen K, Nilsson A, Bosaeus I, Bengtsson BA. Growth hormone increases bone mineral content in postmenopausal osteoporosis: a randomized placebo-controlled trial. J Bone Miner Res 2003; 18 (3): 393-405.

9. White HD, Ahmad AM, Syed AA et al. Gender variation in PTH sensitivity and rhythmicity following growth hormone replacement in adult growth hormone-deficient patients. Clin Endocrinol (Oxf) 2004; 60 (4): 516-526.

10. Giustina et al. Growth hormone, Insulin like growth factors and the skeleton. Endocrine Rev 2008; 29 (5): 535-559.

11. Bex M, Abs R, Maiter D, Beckers A, Lamberigts G, Bouillon R. The effects of growth hormone replacement therapy on bone metabolism in adult-onset growth hormone deficiency: a 2-year open randomized controlled multicenter trial. J Bone Miner Res 2002; 17: 1081-1094.
12. Hansen TB, Brixen K, Vahl $\mathbf{N}$ et al. Effects of 12 months of growth hormone $(\mathrm{GH})$ : treatment on calciotropic hormones, calcium homeostasis, and bone metabolism in adults with acquired GH deficiency: a doubleblind, randomized, placebo-controlled study. J Clin Endocrinol Metab 1996; 81: 3352-3359.

13. Gotherstrom G, Svensson J, Koranyi J et al. A prospective study of 5 years of GH replacement therapy in GH-deficient adults: sustained effects on body composition, bone mass, and metabolic indices. J Clin Endocrinol Metab 2001; 86: 4657-4665.

14. ter Maaten JC, de Boer H, Kamp O, Stuurman L, van der Veen EA. Long-term effects of growth hormone $(\mathrm{GH})$ : replacement in men with childhood-onset GH deficiency. J Clin Endocrinol Metab 1999; 84: 2373-2380.

15. Colson A, Brooke AM, Walker D et al. Growth hormone deficiency and replacement in patients with treated Cushing's disease, prolactinomas and non-functioning pituitary adenomas: effects on body composition, glucose metabolism, lipid status and bone mineral density. Horm Res 2006; 66: 257-267.

16. de Paula FJ, Góis-Júnior MB, Aguiar-Oliveira MH et al. Consequences of lifetime isolated growth hormone $(\mathrm{GH})$ : deficiency and effects of short-term GH treatment on bone in adults with a mutation in the GHRHreceptor gene. Clin Endocrinol (Oxf) 2009; 70 (1): 35-40.

17. Rota F, Savanelli MC, Tauchmanova L, Savastano S, Lombardi G, Colao A, Di Somma C. Bone density and turnover in young adult patients with growth hormone deficiency after 2-year growth hormone replacement according with gender. J Endocrinol Invest 2008; 31 (2): 94-102.

18. Hansen TB, Brixen K, Vahl N et al. Effects of 12 months of growth hormone $(\mathrm{GH})$ : treatment on calciotropic hormones, calcium homeostasis, and bone metabolism in adults with acquired GH deficiency: a doubleblind, randomized, placebo-controlled study. J Clin Endocrinol Metab 1996; 81: 3352-3359.

19. Koranyi J, Svensson J, Gotherstrom G, Sunnerhagen KS, Bengtsson B, Johannsson G. Baseline characteristics and the effects of five years of GH replacement therapy in adults with GH deficiency of childhood or adulthood onset: a comparative, prospective study. J Clin Endocrinol Metab 2001; 86: 4693-4699.

20. Francisco JA, de Paula, Miburge B, Góis-Júnior, Manuel H, Aguiar-Oliveira et al. Consequences of lifetime isolated growth hormone $(\mathrm{GH})$ : deficiency and effects of short-term $\mathrm{GH}$ treatment on bone in adults with a mutation in the GHRH-receptor gene. Clin Endocrinol (Oxf) 2009; 70 (1): $35-40$.

21. Molitch et al. Evaluation and Treatment of Adult Growth Hormone Deficiency: An Endocrine Society Clinical Practice Guideline. J Clin Endocrinol Metab 2006; 91 (5): 1621-1634.

22. Giustina A, Licini M, Bussi AR et al. Effects of sex and age on the growth hormone response to galanin in healthy human subjects. J Clin Endocrinol Metab 1993; 76: 1369-1372.

23. Veldhuis JD. Gender differences in secretory activity of the human somatotropic (growth hormone): axis. Eur J Endocrinol 1996; 134: 287-295.

24. Giustina A, Scalvini T, Tassi C et al. Maturation of the regulation of growth hormone secretion in young males with hypogonadotropic hypogonadism pharmacologically exposed to progressive increments in serum testosterone. J Clin Endocrinol Metab 1997; 82: 1210-1219.

25. Rossini A, Lanzi R, Losa $M$ et al. Predictors of bone responsiveness to growth hormone $(\mathrm{GH})$ : replacement in adult $\mathrm{GH}$-deficient patients. Calcif Tissue Int 2011; 88 (4): 304-313. 
26. Drake WM, Rodríguez-Arnao J, Weaver JU et al. The influence of gender on the short and long-term effects of growth hormone replacement on bone metabolism and bone mineral density in hypopituitary adults: a 5-year study. Clin Endocrinol (Oxf) 2001; 54 (4): 525-532.

27. Ueland T, Odgren PR, Yndestad A et al. Growth hormone substitution increases gene expression of members of the IGF family in cortical bone from women with adult onset growth hormone deficiency - relationship with bone turnover. Bone 2003; 33 (4): 638-645.

28. Ohlsson C, Bengtsson BA, Isaksson OG, Andreassen TT, Slootweg MC. Growth hormone and bone. Endocr Rev 1998; 19: 55-79.

29. Killinger Z, Payer J, Lazúrová I et al. Arthropathy in acromegaly. Rheum Dis Clin North Am 2010; 36 (4): 713-720.

30. Elbornsson M, Götherström G, Franco C, Bengtsson BA, Johannsson G, Svensson J. Effects of 3-year growth hormone (GH): replacement therapy on bonemineral density in younger and elderly adults with adult onset GH deficiency. Eur J Endocrinol 2011; 21.

31. Hyldstrup L, Conway GS, Racz K et al. Growth hormone effects on cortical bone dimensions in young adults with childhood-onset growth hormone deficiency. Osteoporos Int 2011; 29.
32. Conway GS, Szarras-Czapnik M, Racz K et al. 1369 GHD to GHDA Transition Study Group. Treatment for 24 months with recombinant human $\mathrm{GH}$ has a beneficial effect on bone mineral density in young adults with childhood-onset GH deficiency. Eur J Endocrinol 2009; 160 (6): 899-907.

33. Mazziotti G, Bianchi A, Bonadonna $S$ et al. Increased prevalence of radiological spinal deformities in adult patients with GH deficiency: influence of GH replacement therapy. J Bone Miner Res 2006; 21: 520-528.

34. Wuster C, Abs R, Bengtsson BA et al. KIMS Study Group and the KIMS International Board. Pharmacia, Upjohn International Metabolic Database 2001 The influence of growth hormone deficiency, growth hormone replacement therapy, and other aspects of hypopituitarism on fracture rate and bone mineral density. J Bone Miner Res 2001; 16: 398-405.

35. Mazziotti G, Bianchi A, Cimino V et al. Effect of gonadal status on bone mineral density and radiological spinal deformities in adult patients with growth hormone deficiency. Pituitary 2008.

36. Vestergaard P, Jorgensen JO, Hagen $\mathbf{C}$ et al. Fracture risk is increased in patients with $\mathrm{GH}$ deficiency or untreated prolactinomas - a case control study. Clin Endocrinol (Oxf) 2002; 56: 159-167.

Received February 8, 2012. Accepted September 20, 2013. 